\title{
The net neutrality debate on Twitter
}

\section{Wolf J. Schünemann}

Institute of Political Science, Universität Heidelberg, Germany

\section{Stefan Steiger}

Institute of Political Science, Universität Heidelberg, Germany

\section{Sebastian Stier}

Institute of Political Science, Universität Heidelberg, Germany

Published on 21 Dec 2015 | DOI: 10.14763/2015.4.394

\begin{abstract}
The internet has been seen as a medium that empowers individual political actors in relation to established political elites and media gatekeepers. The present article discusses this "net empowerment hypothesis" and tests it empirically by analysing Twitter communication on the regulation of net neutrality. We extracted 503.839 tweets containing \#NetNeutrality posted between January and March 2015 and analysed central developments and the network structure of the debate. The empirical results show that traditional actors from media and politics still maintain a central role.
\end{abstract}

Keywords: Net empowerment, Net neutrality, Political participation, Network analysis

\section{Article information}

Received: 02 Aug 2015 Reviewed: 05 Dec 2015 Published: 21 Dec 2015

Licence: Creative Commons Attribution 3.0 Germany

Competing interests: The author has declared that no competing interests exist that have influenced the text.

URL: http://policyreview.info/articles/analysis/net-neutrality-debate-twitter

Citation: Schünemann, W. J. \& Steiger, S. \& Stier, S. (2015). The net neutrality debate on Twitter. Internet Policy Review, 4(4). https://doi.org/10.14763/2015.4.394

\section{INTRODUCTION}

Social science literature on the relationship between internet development and democracy has featured controversial discussions between a teleological and almost utopian hypothesis and more critical or nuanced positions.1 The "net empowerment" hypothesis views online communication as an instrument to empower the democratic citizen, enabling him or her to more directly engage in democratic decision-making, thereby approaching ideal conceptions of direct or strong democracy (Barber, 1994). Since each internet user can produce and distribute political content (Bruns, 2009), established elite-driven political procedures and media 
gatekeepers are replaced by fluid online communication and less hierarchical networks; or in Shirky's words, by “everybody” (Shirky, 2008).

To elaborate on these expectations, this paper analyses Twitter communication on the regulation of net neutrality. Does political conflict during the policy debate open up to ad hoc groups and individual activists, or do traditional actors preserve their important roles? The regulation of data and information flows on the internet is a policy question of central importance to the online and civil rights communities and therefore constitutes a favourable case to test the participatory hypothesis. Empirically, we provide temporal and network analyses of the central debate hashtag \#NetNeutrality to assess the policy-specific relevance of particular user groups. Our findings show limited evidence of an opening up of political participation, as the traditional actors in media and politics seem to preserve their influential roles, or at least retake them when it comes to policy-making.

\section{INTERNET AND DEMOCRACY}

New internet technologies and social media in particular have generated hopes regarding the general democratic development and the empowerment of individual actors in political participation.2 We define political elites and news media as traditional actors as opposed to individual activists, highly individualised online media and new forms of self-publishing. This differentiation is very common in the literature on net empowerment. Relying on established gatekeeping theories in many fields of research (Barzilai-Nahon, 2009; Goode, 2010; Sarcinelli, 2014; Shoemaker \& Reese, 1996; Singer, 2001), Shirky introduces three criteria for distinguishing traditional media as professionalised organisations from emerging forms of online journalism:

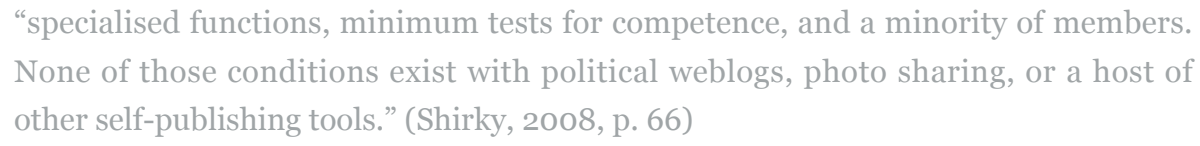

In line with notions of net empowerment, networked information economy or networked public sphere, one could, like Yochai Benkler, expect that:

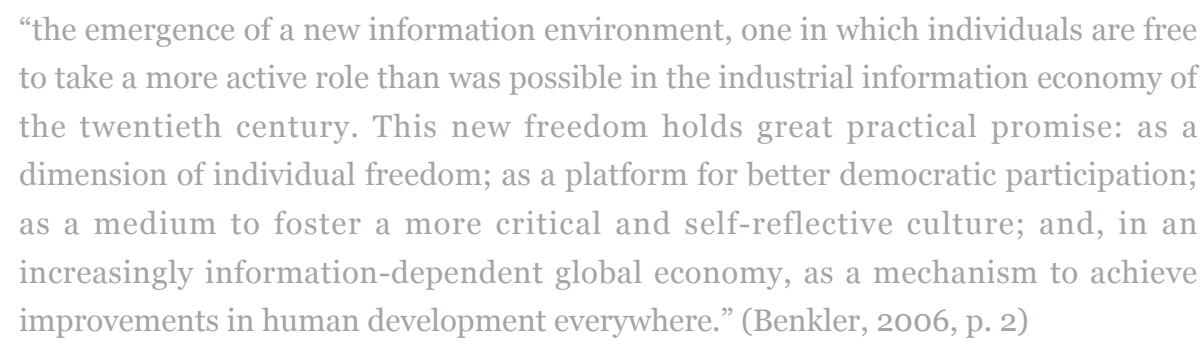

This abstract promise has become concrete in at least three strands of expectations. First, the proponents of a supplementation of representative democracy through direct democratic instruments and more direct participation emphasised the potential of communication first in the computer and then in the internet era from their beginnings (Barber, 1994). Besides that, a second strand of euphoric expectations emerged, which has not so much been aimed at 
constitutional reform towards more participation, but rather expected a fundamental challenge of the elite-driven institutions and processes of representative democracy, emerging from the communicative realities of networked societies (Shirky, 2008). Traditional political elites and media gatekeepers would be more and more challenged or even replaced by 'everybody', by the grassroots or netroots of networked societies (Bruns, 2009; Shirky, 2008; critical perspectives in Hindman, 2009, p. 102; Schünemann, 2012). Finally, a third body of literature has transferred these euphoric assumptions into a new democratisation scenario focussed on citizen upheavals in a row of autocracies. These authors see the internet and other ICTs as existential challenges or threats to autocratic regimes across the world (Diamond, 2012; Howard \& Hussain, 2011).

In clear contrast to high expectations, critical enquiries into the implications of the internet on democratic development have already unveiled disappointment. Euphoric expectations have provoked strong counter-arguments and criticism (Kneuer \& Demmelhuber, 2012; Morozov, 2011). While many observers generally confront participatory innovations with paradoxical empirical results ("The populist paradox", Gerber, 1999), the supposed contradictory effects, such as an increased elite bias in comparison to representative modes of decision-making, seem to be particularly accurate in the case of online participation ("reinforcement hypothesis", Davis, 1999). Hindman's study of political blogs in the United States points in this direction. He shows a clear resemblance between the opportunity structures and realities of political participation in the digital age and pre-internet times:

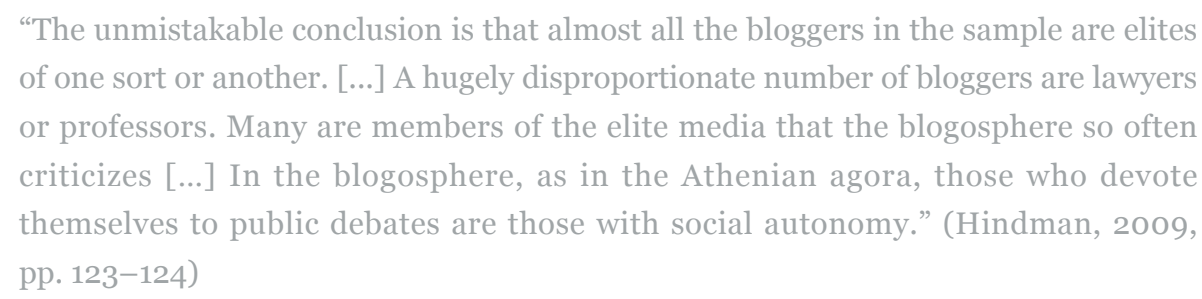

However, with regard to the opportunity structures for new forms of politics and democracy, the internet has certainly changed the media environment and political communication (Chadwick, 2013). Especially social media or social networks that are so central to the second phase of internet development (web 2.0) literally imply the promise of some sort of social integration capacity. For domestic politics, they provide new modes of participation and can play "an important role in the organisation and mobilisation of campaigns and political protests" (Kneuer, 2013, p. 14). Moreover, many observers see social media as challenging mass media and their gatekeeping function for the political public (Sarcinelli, 2014, p. 334).

By analysing Twitter communication, we have intentionally selected the social network that with its issue-oriented communication most likely constitutes a functional equivalent to traditional media (Kwak et al., 2010). It is therefore used intensively by political actors for the dissemination of policy ideas, the communication of news and the organisation of collective action (Jeffares, 2014). Thus, Twitter incorporates ambitions of a more accessible and intensive culture of political communication and a diversification of the media system. We are interested in an extension of participation within the domestic realm, across different institutional forms, including new actors and a broader public. In line with this, we expect that forms of discursive networking via Twitter and other online media have direct as well as more diffuse repercussions on political negotiations and produce interaction processes with political debates. We streamed the Twitter communication on \#NetNeutrality to analyse the development of an on-going policy 
debate and the structure of the related online network.

\section{THE NET NEUTRALITY DEBATE}

Net neutrality is a core issue of internet governance. The community of so called netizens mobilises against the new business visions of telecommunication companies, in which they see an assault on the original idea of the internet. Net neutrality proponents make the case for a nationally or internationally guaranteed commitment to an equal treatment of data packages on the internet and the prohibition of any zero rating services that privilege certain content providers over their competitors. The principle of net neutrality thus matters for the liberal (or libertarian) self-understanding of netizens.

The movement for net neutrality is supported by some governments, such as the U.S. administration. In November 2014, President Obama urged the politically independent oversight commission Federal Communications Commission (FCC) to regulate in favour of net neutrality. After intense public debate at different stages of the policy process, the FCC announced a decision to be made in the beginning of 2015. In light of the clear leadership role of the U.S. in internet governance issues, the FCC regulation was highly anticipated and was seen as a worldwide role model for regulations on this issue.3 However, political conflicts emerged along well-known partisan divisions and the issue became more and more politically polarised. Democrats see net neutrality as an important cornerstone of an equal economic and political playing field on the internet and as an efficient customer protection. In contrast, Republicans regard net neutrality as an illegitimate government overreach into the economy, illustrated by a frequently retweeted and cited tweet by Republican Senator and presidential candidate Ted Cruz: "Net neutrality' is Obamacare for the internet; the internet should not operate at the speed of government." However, the FCC regulation pronounced a clear commitment to the principle of net neutrality.

The fundamental regulation question has become a contentious issue in many other countries at the same time and it regularly reaches daily politics. However, regarding legislative output, the EU constitutes a slightly different example, as the telecommunication sector falls under its supranational competences. Recently, the net neutrality issue has provoked tensions between the two legislating institutions. While the European Parliament, after a strong campaign by European digital rights organisations, positioned itself in favour of net neutrality, the Council (comprised of national EU governments) presented a divergent position in March 2015, which was more in line with the interests of big service providers (Council of the EU, 2015). In the trialogue meetings of mid-2015, the institutions agreed on rules that the European Parliament finally passed at the end of October (European Commission, 2015). The new rules are meant to prevent Internet Service Providers from slowing down internet traffic or from blocking content in order to require additional charges. However, the considerable exceptions have earned much criticism from internet activists who would have preferred an unimpaired commitment to the net neutrality principle as shown by the US government.

In order to assess the potential for intense political conflict that can influence decision making on this sort of regulation, we start with the assumption that political mobilisation among internet users is especially high when self-referential questions, i.e. the regulation of cyberspace, are at stake. This is even more likely, when substantial issues and principles of online communication are affected by regulation. Thus, the massive mobilisation of transnational netizen communities against the anti-counterfeiting agreement ACTA might serve as a 
comparable case. After years of negotiations and at the end of an international decision-making process, the effectively articulated protests of transnationally networked user groups caused an important political turnaround (Kneuer, 2013, p. 7; Matthews \& Žikovská, 2013). The interviewbased study of Dür and Mateo showed the interplay between a favourable public opinion and citizen group influence. Motivated by a relatively high public salience of the issue that had been successfully increased by interest groups, many activists and citizen groups stepped in and actively campaigned against the agreement. These activities finally provoked the turnabout of decision-makers, as the authors argue (Dür \& Mateo, 2014).

Overall, following the participatory hypothesis, the openness and accessibility of Twitter networks should reflect an empowerment of civil society groups and activists in comparison to political elites and traditional media. However, since net neutrality is also on the mainstream political agenda, especially as a partisan policy debate in the U.S., it is possible that actor constellations from the political system offline are reflected in the online networks. Thus, in accordance with the normalisation hypothesis in communication studies, it is possible that the political and economic capital of established actors translates into a higher network centrality in Twitter debates.

\section{METHODS AND DATA}

We collected the metadata and contents of 503.839 tweets and retweets containing the hashtag \#NetNeutrality posted between 14 January and 6 March 2015. Twitter hashtags can be considered as topical query terms that serve "as a vehicle for otherwise unconnected participants to be able to join in a distributed conversation” (Bruns \& Burgess 2011, p. 49).4 Because of its public character and its communication structure that is mostly topic-centered, we consider Twitter to be a best case for political activism. This does not necessarily apply to other, more private social networks like Facebook. For most of our analyses and data cleaning tasks we used the open source software $\mathrm{R}$ and in particular its package streamR (Barberá 2014). The network analysis was performed using the visualisation software Gephi.

The undirected network graph is constructed taking users as its nodes and mentions and retweets as its edges. We used the PageRank algorithm to determine the network centrality of users taking into account all information on the connections of the other actors in the network. That way, the "popularity" of an actor is not only based on its incoming references (indegree), but also on his/her own activity to shape the debate through tweets and retweets. This procedure takes the interactions and dynamics of the evolving net neutrality debate into account. However, the methodological focus on metadata restrains the interpretation of the data, as information with regard to the intentions of mentions and retweets can only be inferred from detailed content analyses. Therefore, the interpretation of debate structures is grounded in graph theory, i.e. actor positions are assessed in terms of their network centrality.

In general, the analysis of social behaviour on the internet suffers from uncertainties that are inherent to the medium (cf. the overviews in: boyd \& Crawford, 2012; Ruths \& Pfeffer, 2014). The streaming of tweets using the API for instance is restricted to $1 \%$ of real time Twitter traffic. 5 Moreover, besides relevant messages, communication in social networks produces a lot of "noise", e.g., spam and automated messages sent from bots that distort political debates.6 Naturally, the Twitter population and its subgroup of politically active users are not representative mirrors of offline populations. In particular, the latter caveat has to be kept in mind when interpreting the empirical results. However, since we only concentrate on the 
structure of online debates and do not infer the results from our findings to the offline world, the population bias inherent to Twitter is negligible in this context.

\section{FINDINGS AND DISCUSSION}

Figure 1 shows the temporal distribution of tweets containing the hashtag \#NetNeutrality. The unfolding of the debate corresponds to developments in the U.S. policy debate, as attention spikes can be traced to the activities of central political actors, mostly from the American public sphere.

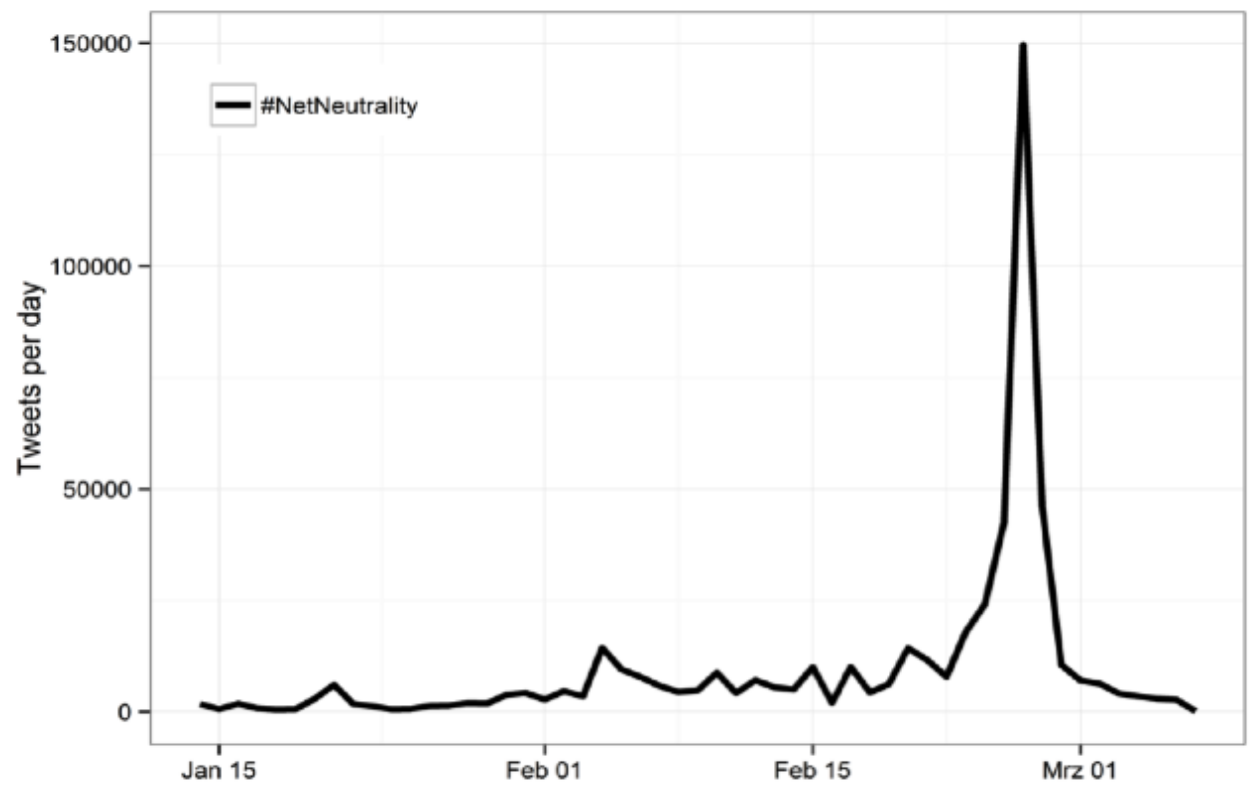

Figure 1: Tweets on \#NetNeutrality between 14 January and 6 March 2015.

The debate became particularly intense with an increasing partisan divide regarding the regulation of net neutrality. The peak on 21-22 January is related to Barack Obama's State of the Union Address in which the President proposed a "free and open internet" and subsequent congressional hearings on the topic. On 4 February, FCC Chairman Tom Wheeler announced his intention to advocate the principle of net neutrality in his regulation proposal to his commission. Wheeler proclaimed his announcement with tweets using the \#NetNeutrality hashtag that were retweeted more than 1.000 times and celebrated by the activist community.7 Until the FCC finally announced its long awaited regulatory decision, net activists and NGOs such as Fight for the Future launched Twitter campaigns animating internet users to write or tweet to their members of Congress. Over time, a considerable mobilisation by regulation opponents emerged, originating for instance from activists from Tea Party groups or from prominent opponents like libertarian and EFF co-founder John Perry Barlow and internet entrepreneur Marc Cuban.8 The final decision of the FCC was accompanied by more than 238.00o tweets on 25-27 February. Mass media reported extensively on the decision, the New York Times called the struggle for net neutrality the "longest, most sustained campaign of internet activism in history." Civil society organisations, NGOs and political figures such as President Barack Obama, Senator John McCain and the Speaker of the House John Boehner connected their official statements to the Twitter debate by using the hashtag \#NetNeutrality.

The dynamic developments within the mainstream U.S. policy debate find expression in activity 
peaks in the Twitter debate that seems to follow their lead. This first finding deviates to a certain extent from Faris et al. (2015) who regard non-traditional actors as the main agenda setters. Since their research period ends in November 2014, it is to be assumed that the debate structure significantly shifted from a phase dominated by bottom-up activism to an institutionalised policy debate that resembles the established political system. We would therefore argue that while "networked collective action" might have been instrumental to politicise the issue in the first place, the policy debate itself mostly centred on established political actors and media gatekeepers. The following network analysis can further improve our understanding of the network structure and actor relationships.

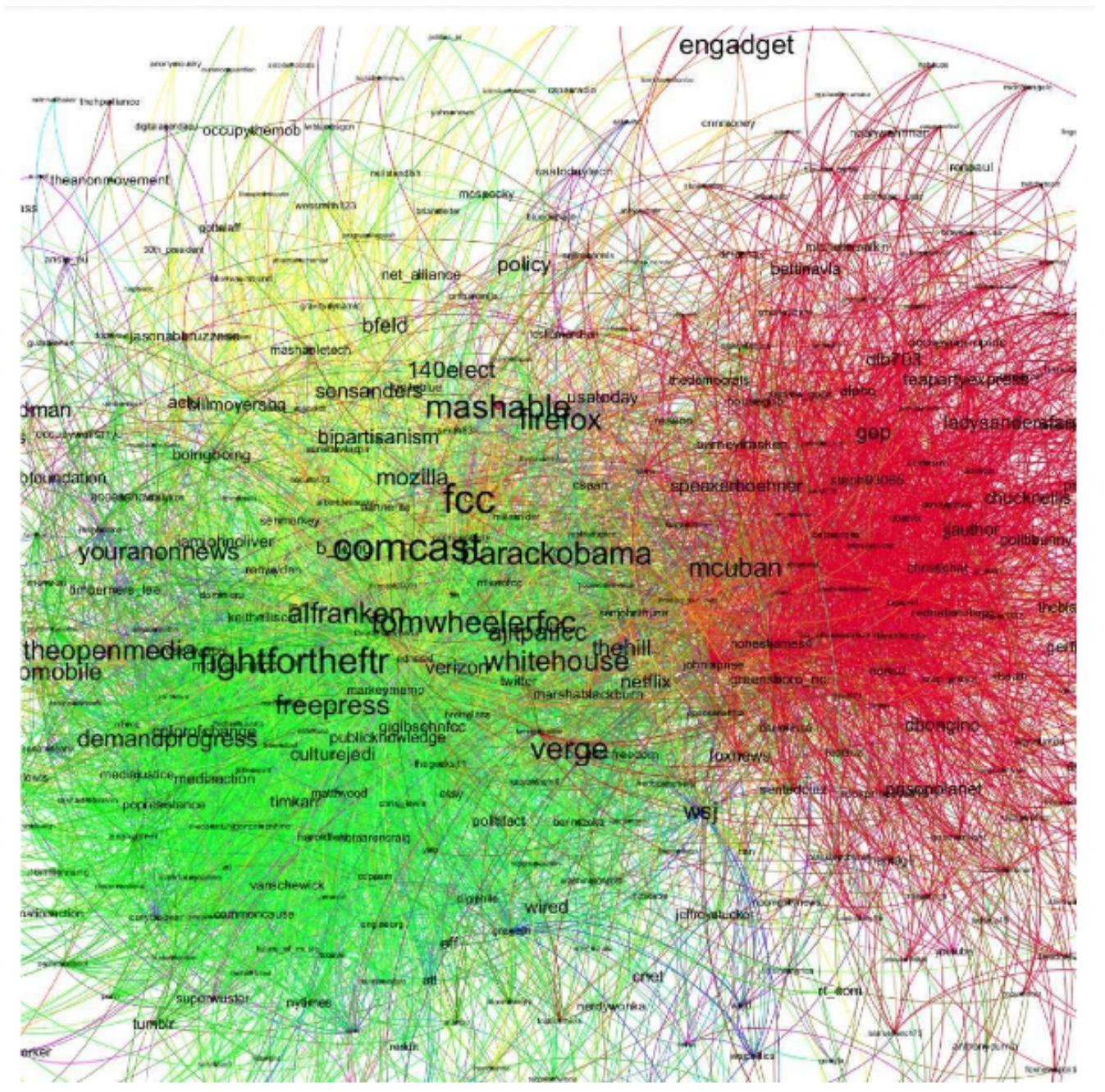

Figure 2: Twitter network on \#NetNeutrality

Figure 2 displays the results of the network analysis. For illustrative reasons, we restricted the graphs to the 500 actors with the highest PageRanks.9 The \#NetNeutrality network features U.S. American actors from different spheres: politics, business and media.1o The network centrality of the FCC and its chairman Tom Wheeler reflects the domestic policy debate. We can observe a significant political polarisation, with proponents of net neutrality on the left side and critics of FCC regulation on the right. The network separation depicts the tendency of actors on both sides to predominantly name, link and share content with users in the same camp. The Democratic Party argued that the FCC had the right to set legal regulations binding the telecommunication sector to net neutrality in order to guarantee consumer protection and to promote innovation in digital communication. In clear contradiction, the Republicans argued that such a regulation 
would trespass the competences of a federal regulation commission and that it would constitute an illegitimate market intervention.

Among the proponents, we find a number of NGOs from the liberal-progressive spectrum, civil rights movements such as the Electronic Frontier Foundation or Demand Progress, individual activists and the hacker group Anonymous. The high PageRanks of the main net neutrality advocacy groups Fight for the Future, Free Press and The Open Media, as indicated by the size of their labels, and their central position in the supporter camp illustrate that well-organised internet activism can have an impact in Twitter debates. This finding concurs with the network analysis of Faris et al. (2015).

In the centre of the graph, there are media figures like the Wall Street Journal, CSPAN, The Hill and Verge that are regularly referenced by both conflicting camps. Some media, like the New York Times and Wired, are placed on the left, while Fox News is situated on the right. Business actors are mostly on the left side of the network. One clear exception is telecommunication entrepreneur Mark Cuban who is among the critics. While the arrangement in the pro-camp of internet companies like Mozilla, Tumblr, and Reddit that have lobbied publicly for net neutrality seems logical, the same positioning of internet service providers such as Comcast and Verizon is rather counter-intuitive. Looking at the content level, it becomes clear that net neutrality proponents were frequently referring to them as bogeymen via @-mentions (see also Faris et al., 2015). This explanation needs to be substantiated by a systematic qualitative examination of the data and again points to the limitations of a metadata-based research design.

The camp of critics is composed of Republican politicians such as Ted Cruz, Ron Paul, John Boehner, the accounts of the GOP, the Republican National Committee as well as other conservative groups and activists, for example, from the Tea Party movement. The existence of such a quantitatively significant opposition is the main difference compared to the paper of Faris et al., which finds that the "debate in digital media over net neutrality is heavily skewed towards proponents of net neutrality" (2015, p. 30). President Obama's endorsement of net neutrality on 10 November might have contributed to the increasing partisan polarisation. The Twitter debate therefore seems to have transformed from an advocacy network driven by activism to a policy network that more closely resembles the offline political system. This might indicate that the so-called normalisation in political participation does not depend as much on a particular topic, but on the phase in a policy cycle.

Several issue specific NGOs are quite successful in using Twitter to increase their public outreach and extend their network. Groups like Fight for the Future and Demand Progress lobbied extensively for net neutrality and gathered a significant followership on Twitter. However, our findings mainly illustrate the persistence of offline patterns in cyberspace and contradict the expectations of "here comes everybody" (Shirky, 2008). Elite actors in politics and mass media gatekeepers integrate the online channels into their communication strategies, quite in line with the "media hybridisation hypothesis" (Chadwick, 2013). However, since the U.S. is an outlier regarding the adaptation of online communication by political actors (Stier, 2012), it remains to be seen whether this finding can be generalised.

\section{CONCLUSION}

Our study speaks for a "normalisation" of democratic communication in the internet era, in line with previous empirical studies (e.g., Hindman, 2009). With regard to the limitations of the 
study, the research period chosen clearly reflects the latter stages of the U.S. policy debate on net neutrality. Knowledge of concrete mechanisms linking Twitter debates to policy making generally remains limited. While the policy position of President Obama and the Democratic Party surely influenced the final decision taken by the FCC, their support might have also been shaped by the online activism during the year 2014. An extension of the \#NetNeutrality streaming into the past to include the time frame of Faris et al. (2015) could alter the presented results. However, our findings already indicate a structural shift in the debate from a phase of intense advocacy by activists preceding the policy debate that primarily features elite actors.

The high network centrality of the internet service providers illustrates the need to methodologically expand the analysis, e.g., by differentiating between mentions supporting central actors on the one hand and those pressuring them to take a certain action on the other hand. Furthermore, we chose a very basic definition of participation. Further works might also differentiate several degrees of participation in order to identify more nuanced participatory patterns. For social media in particular, we assume that political participation is not uniform, as superficial forms of participation (liking a message, sharing content, etc.) come along with more substantial contributions to debates. One avenue for such further research is to move beyond metadata and analyse tweets using discourse analytical procedures. This could help to differentiate the normalisation hypothesis as political communication online and offline can be expected to diverge not only in structure but also in style and content.

The debate development and network structure of \#NetNeutrality reveal a dialectic interplay between established structures of representative democracy and debates on social media. While the network analysis shows that several issue specific NGOs broadened their audience using new social media, the study also shows that "everybody" is not prominently featured, as individual activists and self-publishers rarely succeed in attaining a more central position in the network. This finding should, at least, be transferable to national or transnational policy debates that are bound to mainstream political agendas and conflicts. With regard to further assumptions for future studies, scholars should turn to nuanced theories that consider the characteristics of the emerging "hybrid media system" (Chadwick, 2013). Approaches might incorporate the notion of "Fifth Estate" (Dutton \& Dubois, 2015) or the "gatewatching" function of individual actors instead of "gatekeeping" (Bruns \& Highfield, 2015). 


\section{REFERENCES}

Barber, B. R. (1994). Starke Demokratie. Über die Teilhabe am Politischen. Hamburg:

Rotbuch-Verl.

Barberá, P. (2014b). Package 'streamR'.

http://cran.r-project.org/web/packages/streamR/index.html. Last checked on 21 February 2015 .

Barzilai-Nahon, K. (2009). Gatekeeping: A critical review. Annual Review of Information Science and Technology, 43(1): 1-79.

Benkler, Y. (2006). The wealth of networks. How social production transforms markets and freedom. New Haven, Conn. [u.a.]: Yale Univ. Press.

boyd, d., \& Crawford, C. (2012). Critical questions for Big Data. Information, Communication \& Society 15 (5): 662-679.

Bruns, A. (2009). Blogs, Wikipedia, Second Life and Beyond: From Production to Produsage. New York: Peter Lang.

Bruns, A., \& Burgess, J. (2011). \#Ausvotes: How twitter covered the 2010 Australian federal election. Communication, Politics \& Culture 44 (2): 37-56.

Bruns, A., \& Highfield, T. (2015). From news blogs to news on Twitter: gatewatching and collaborative news curation. In S. Coleman \& D. Freelon (Eds.), Handbook of digital politics (pp. 325-340). Cheltenham, UK, Northampton, MA: Edward Elgar Pub.

Chadwick, A (2013). The hybrid media system. Politics and power. Oxford: Oxford University Press.

Council of the European Union. (2015). Roaming and open internet: Council ready for talks with EP. Brussels. Retrieved from

http://www.consilium.europa.eu/en/press/press-releases/2015/o3/150304-roaming-and-open -internet-council-ready-for-talks-with-ep/.

Davis, R. (1999). The web of politics: The internet's impact on the American political system. New York: Oxford University Press.

Diamond, L. (2012). The Coming Wave. Journal of Democracy, 23(1): 5-13.

Dür, A., \& Mateo, G. (2014). Public opinion and interest group influence: how citizen groups derailed the Anti-Counterfeiting Trade Agreement. Journal of European Public Policy, 21(8): $1199-1217$.

Dutton, W. H., \& Dubois, E. (2015). The Fifth Estate: a rising force of pluralistic accountability. In S. Coleman \& D. Freelon (Eds.), Handbook of digital politics (pp. 51-66). Cheltenham, UK, Northampton, MA: Edward Elgar Pub.

European Commission. (2015). Bringing down barriers in the Digital Single Market: No roaming charges as of June 2017. Brussels. Retrieved from

http://europa.eu/rapid/press-release_IP-15-5927_en.htm 
Faris, R., Roberts, H., Etling, B., Othman, B., Benkler, Y. (2015). Score another one for the internet? The role of the networked public sphere in the U.S. net neutrality policy debate. Berkman Center Research Publication No. 2015-4.

https://cyber.law.harvard.edu/sites/cyber.law.harvard.edu/files/

2015_02_10_Score_Another_One_for_the_Internet_o.pdf

Gerber, E. R. (1999). The populist paradox. Interest group influence and the promise of direct legislation. Princeton, NJ: Princeton University Press.

Goode, L. (2010). Social news, citizen journalism and democracy. New Media \& Society, 11(8): 1287-1305.

Hindman, M. S. (2009). The myth of digital democracy. Princeton, NJ: Princeton University Press.

Howard, P. N., \& Hussain, M. M. (2011). The Upheavals in Egypt and Tunisia. The role of digital media. Journal of Democracy, 22(3): 35-48.

Jeffares, S. (2014). Interpreting hashtag politics: Policy ideas in an era of social media. Houndmills, Basingstoke, Hampshire, New York: Palgrave Macmillan.

Knaut, A. (2012). Politisches Gezwitscher von Bundestags- und Europaabgeordneten: Twitter als Schnittstelle zwischen transnationalen Diskursräumen. In W. J. Schünemann \& S. Weiler (Eds.), E-Government und Netzpolitik im europäischen Vergleich (pp. 389-412). Baden-Baden: Nomos-Verlag.

Kneuer, M. (2013). Bereicherung oder Stressfaktor? Überlegungen zur Wirkung des Internets auf die Demokratie. In M. Kneuer (Ed.), Veröffentlichungen der Deutschen Gesellschaft für Politikwissenschaft: Vol. 31. Das Internet: Bereicherung oder Stressfaktor für die Demokratie? (pp. 7-31). Baden-Baden: Nomos.

Kneuer, M., \& Demmelhuber, T. (2012). Die Bedeutung Neuer Medien für die Demokratieentwicklung: Überlegungen am Beispiel des Arabischen Frühlings. Informationen zur Politischen Bildung, (Medien und Politik), 30-38.

Kwak, H., Lee, C., Park, H., \& Moon, S. (2010). What is Twitter, a social network or a news media? In M. Rappa \& P. Jones (Eds.), Proceedings of the 19th international conference on World wide web (pp. 591-6oo). New York: ACM.

Lotan, G., Graeff, E., Ananny, M., Gaffney, D., Pearce, I., \& boyd, d. (2011). The revolutions were tweeted: Information flows during the 2011 Tunisian and Egyptian revolutions. International Journal of Communication 5: 1375-1405.

Matthews, D., \& Žikovská, P. (2013). The Rise and Fall of the Anti-Counterfeiting Trade Agreement (ACTA): Lessons for the European Union. IIC - International Review of Intellectual Property and Competition Law 44 (6): 626-655.

Morozov, E. (2011). The Net delusion: The dark side of internet freedom. New York: PublicAffairs.

Norris, P., \& Curtice, J. (2008). Getting the message out: A two-step model of the role of the internet in campaign communication flows during the 2005 British general election. Journal of 
Information Technology \& Politics 4 (4): 3-13.

Ruths, D., \& Pfeffer, J. (2014). Social media for large studies of behavior. Science 346 (6213): 1063-1064.

Sarcinelli, U. (2014). Von der Bewirtschaftung der Aufmerksamkeit zur simulativen Demokratie?: Politische Visionen - Von Platon zum Global Village. Zeitschrift für Politikwissenschaft, 24(3): 331-341.

Schünemann, W. J. (2012). E-Government und Netzpolitik - eine konzeptionelle Einführung. In W. J. Schünemann \& S. Weiler (Eds.), E-Government und Netzpolitik im europäischen Vergleich (pp. 9-38). Baden-Baden: Nomos-Verlag.

Schünemann, W. J. (2014). Subversive Souveräne: Vergleichende Diskursanalyse der gescheiterten Referenden im europäischen Verfassungsprozess. Theorie und Praxis der Diskursforschung. Wiesbaden: Springer VS.

Singer, J. B. (2001). The Metro Wide Web: Changes in Newspapers' Gatekeeping Role Online. Journalism \& Mass Communication Quarterly, 78(1): 65-80.

Shirky, C. (2008). Here comes everybody: the power of organizing without organizations. New York, NY: Penguin Books.

Shoemaker, P. J., \& Reese, S. D. (1996). Mediating the message: Theories of influences on mass media content (2nd ed.). White Plains, N.Y.: Longman.

Stier, S. (2012). Die Bedeutung des Internets als Medium der politischen Kommunikation in Deutschland und den U.S.A. Eine vergleichende Fallstudie. Münster: LIT.

Thiel, T. (2014). Die Schönheit der Chance: Utopien und das internet.juridikum, (4): 459-471.

\section{FOOTNOTES}

1. See for instance the discussion of utopian expectations in Kneuer (2013) and Thiel (2014).

2. We apply a minimalist conception of political participation, i.e. tweets and retweets of political content.

3. The FCC's regulation is seen as a strong protection of net neutrality as it prohibits broadband providers to block, throttle or prioritise any specific content in order to increase profits.

4. The hashtag \#NetNeutrality was central in the net neutrality debate. Issue-related tweets without this particular hashtag as well as related hashtag "populations" that have emerged during the debate, like \#OpenInternet, have not been queried under this selection criterion.

5. However, this threshold has not been passed at any time during our study.

6. For this reason, the accounts @All4NeutralNet and @RealNeutralNet set up by activists from Demand Progress, were excluded from data collection, since they sent the same citizen petitions to Republican politicians and President Obama in an infinite loop.

7. Tom Wheeler (@TomWheelerFCC): “Our proposed \#NetNeutrality rules ban Internet paid prioritization, blocking, throttling \& strengthen transparency: http://wrd.cm/16nDJn5”. 
8. Their tweets illustrate the argumentation of the opponents fairly well: John Perry Barlow (@JPBarlow): “20 years ago, The Trojan Horse was "What About the Children?" He's returned as \#NetNeutrality”.

Mark Cuban (@mcuban): “The @fcc proposal on \#NetNeutrality is 332 pages and won't be seen till after its voted on. That is who will run the Internet for us \#badidea”.

9. The label size of actors is determined by their PageRanks. The network layout is based on the Fruchterman-Reingold algorithm. Results remain robust when applying the Betweenness centrality algorithm instead of PageRanks.

10. The sheer number of Twitter users in the U.S. is not the only possible explanation for the preponderance of U.S. actors in the respective network. At least, in the research period at hand, Twitter users from across the world refer to the U.S. American policy debate on net neutrality and the respective set of actors. In contrast, as regards the European regulatory conflict on the issue, only the MEP Marietje Schaake reaches a more central position in the network. 